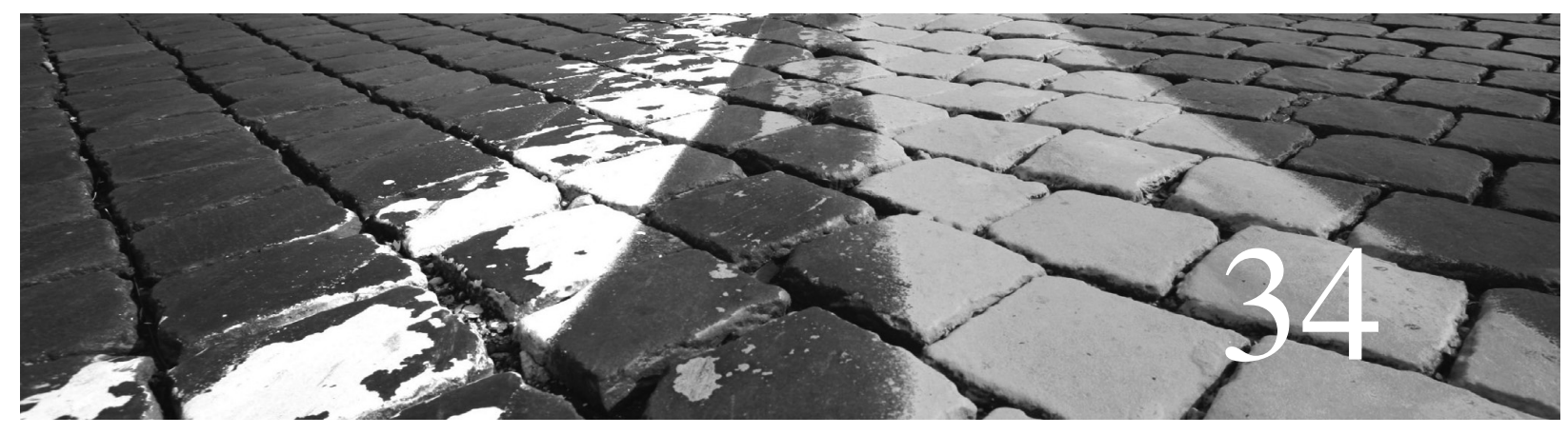

\title{
The Analytic Integration of Qualitative Data Sources
}

\author{
Ann Cronin, Victoria D. Alexander, Jane
} Fielding, Jo Moran-Ellis and Hilary Thomas

\section{INTRODUCTION}

In recent times there has been a considerable growth in research projects using more than one method (see for example, Corden and Sainsbury, 2006; Dicks et al, 2006; Mason, 2006). This has led to renewed debate about the issues involved in using multiple methods in a single study, including questions concerning the different ways in which methods and data could or should be brought together (see for example, Caracelli and Greene, 1997; Moran-Ellis et al, 2006; Pawson, 1995). However, within these debates there is a tendency to focus attention on designs which bring together qualitative and quantitative methods, leaving aside research designs which utilise multiple qualitative methods, perhaps on the assumption that 'qualitative data' is a homogeneous category. In this chapter we examine the issues involved in integrating different types of qualitative data generated through three qualitative methods: 'conventional' in-depth interviews, photo-elicitation interviews, and narrative interviews. Drawing on data from the PPIMs project ${ }^{1}$ (Practice and Process in Integrating Methodologies project), which explored the methodological issues that arise in multi-method and multi-level approaches to investigating the management of vulnerability in everyday life, we specifically focus on the process of achieving integration across these sets of data at the point of analysis and document an approach we call 'following a thread' (Moran-Ellis et al, 2004).

We begin the chapter with a brief overview of the concept of integration before moving on to an outline of our research design. We then set out the framework we developed - 'following a thread' - to achieve the integration of linked but separately generated qualitative datasets at the point of analysis.

\section{CONCEPTUALISING INTEGRATION}

In our own work (Moran-Ellis et al, 2006) we have argued for the importance of the 
conceptualisation of integration as a specific relationship between different methods (and methodologies) which accords equal weight to the findings of all the methods used for answering the research question, does not violate the epistemological or ontological assumptions that underpin them, but does not necessarily lead to any particular knowledge claims concerning validity or complexity. This differs from triangulation approaches which are concerned with the accuracy or interpretive complexity of research findings (see for example Bryman, 2004). Integration of data may be necessary for triangulation, but it is a process of bringing research methods (or datasets) together, whereas triangulation is an epistemological claim. It also differs from other uses of multiple methods: for example research designs where one method is given explanatory precedence and the data from other method(s) are used to support and elaborate on those findings; and those designs where one method is employed to develop the other such as in the use of focus groups to inform questionnaire design. In both these examples the different methods do not contribute equally to the production of explanations of the phenomenon (see Greene et al, 1989 for a more comprehensive review of the different ways in which multiple methods may be used). In effect, our conceptualisation of integration in multiple methods research is analogous to an integrated transport system where buses, trains and perhaps planes are linked together by terminals, connections and timetables. Passengers use different transportation modes for different parts of their journey as appropriate, and each form of transportation retains its own nature whilst also interfacing in a coordinated way with the other means of transport needed for the journey (Moran-Ellis et al, 2006).

Key to this conceptualisation of integration in research is the requirement that each method used retains its own character: different data types are not transformed into one type and then analysed using one analytic method. This retention of methodological character allows the findings of each dataset or method to contribute equally to answering the research question in their own paradigmatic terms, and the methods interface with each other through some kind of designed and systematic juxtaposition.

Integration can be achieved at various points in the research process, from research instrument design through to interpretation of findings (see Brannen, 2004; Moran-Ellis et al, 2004). However, it is frequently the case that integration is deferred until the analysis stage either for pragmatic or theoretical reasons. Such 'analytic integration' is distinct from integration at other stages of the research process, and it is this that we discuss in this chapter. Using data from our PPIMs project we illustrate how analytic integration might be achieved using the framework of 'following a thread'.

\section{THE PPIMS PROJECT}

The PPIMs project used a number of methods to explore the complex dimensions of vulnerability in the everyday lives of a wide range of people living in Hilltown ${ }^{2}$. The project also examined the methodological issues involved in implementing a mixed-methods research design.

The project consisted of small-scale studies that explored participants' understandings, experiences and management of everyday vulnerability. Table 34.1 provides an overview of each of the qualitative small-scale studies (the project also included a small-scale study that used secondary quantitative data but this is not discussed in this chapter).

The concept of vulnerability has been used extensively in both the physical and social sciences to investigate and theorise factors and processes that lead to individuals or groups having raised levels of risk concerning specific negative phenomena or events. Even though recent work has begun to take account of the socially constructed nature of vulnerability, it remains the case that much of the research on vulnerability has been underpinned by a deficit model which assumes that some groups of people are more vulnerable than others because they 
Table 34.1 Overview of the PPIMs qualitative small-scale studies

\begin{tabular}{|c|c|}
\hline Households & $\begin{array}{l}21 \text { in-depth individual interviews and } 3 \text { paired sibling interviews with each member of } \\
6 \text { households containing children/young people and at least one parent. }\end{array}$ \\
\hline Individuals & $\begin{array}{l}28 \text { individual in-depth interviews with } 10 \text { people living on their own and } 21 \text { people living with } \\
\text { at least one other adult. }\end{array}$ \\
\hline $\begin{array}{l}\text { People with experience } \\
\text { of homelessness }\end{array}$ & $\begin{array}{l}1 \text { focus group discussion with } 6 \text { people who had all been homeless at some time. Individual } \\
\text { interviews using a life history approach with } 7 \text { participants. }\end{array}$ \\
\hline Visual follow-on study & $\begin{array}{l}\text { Photo elicitation interviews with } 13 \text { people, based on photographs they took for the study. } \\
\text { Video-recorded neighbourhood journeys with } 8 \text { people. Participants had already participated in } \\
\text { one of the first three parts of the research. }\end{array}$ \\
\hline
\end{tabular}

lack something. For example, people may be classified as 'vulnerable' because they are homeless, children are assumed to be essentially vulnerable, and older people are seen as vulnerable when they lack power and capacity. Undoubtedly the uneven distribution of economic, social and political power in society leads to certain groups of people being at greater risk of adverse events such as ill-health, trauma or material loss. However, this one-sided approach tells us very little about the experiential nature either of being a member of such a group or of feeling vulnerable. Furthermore, designating specific groups of people 'vulnerable' and implying others are 'not vulnerable' leaves us unable to examine how people (regardless of their situation) experience and manage vulnerabilities in everyday life. As Wisner (1991: 128) argues, research on vulnerability needs to "create ways of analysing the vulnerability implicit in daily life', and the coping strategies that people develop to manage these. This conceptualisation of vulnerability points towards the research methods which can capture these experiential aspects.

In the PPIMs project we used three methods to generate qualitative data in respect of the experiential nature of vulnerability: indepth interviews, life histories, and visual methods. These different methods have the potential to tap into different dimensions of vulnerability. For example, verbal accounts of vulnerability elicited through in-depth interviews allow exploration of meanings of vulnerability whereas accounts generated through photo-elicitation interviews may connect with constructions connected to the visual realm. Similarly, accounts generated in interviews may emerge with different coconstructions of vulnerabilities than those generated through life history interviews. Critical reflection on these possibilities points towards the potentially heterogeneous nature of our qualitative datasets and the implications of this for integration of these particular data. One implication concerned analytic approaches to different sets of data, and the question of how to analyse each dataset using an approach appropriate to the nature of that data, so that its epistemological contribution to understanding the phenomenon is realised, whilst also being able to integrate the analyses to produce explanations and understandings which were greater than the sum of the parts.

The in-depth interviews were based on conventional practices of using a broad schedule of topics to guide the interview, and being responsive to participants' own accounts of their experiences and meanings with regard to questions asked. On the basis of this, we considered that the most appropriate analytic approach to the dataset generated through in-depth interviews was that of a grounded thematic analysis. For this the researcher typically begins by examining the data line by line, identifying themes and coding these (see Coffey and Atkinson, 1996), then developing these codings to capture multiple meanings, coding convergence and divergence, and the relationship of codes to broader categories. The process is iterative, and involves segmenting the data. Analysis then proceeds through consideration of codes and categories to develop a thematic level of analysis. 
The practicalities of the process of comparison of segments of data leads to an enduring problem of this type of analysis, namely that the segments are to some extent removed from the contexts of their occurrences within the interview. The development of the thematic analysis requires the research to re-connect segments to contexts in order to derive legitimate interpretations of the data.

The visual study component of the project was based on two visually rooted methods: photo-elicitation interviews based on photographs, and video-recorded neighbourhood tours. In this chapter we focus on the verbal dataset generated through the photo-elicitation interviews. Photo-elicitation interviews involve participants discussing photographs with the researcher. In our study, participants themselves generated the photos about which they were interviewed. Collier (1967), an early advocate of this technique, suggests that the use of photographs during interviews helps frame and focus the discussion, sharpen memory, evoke rich descriptions and set the informant at ease. The interview enables participants to discuss their interpretation and meaning of the photographs and to provide an explanation for why they chose to photograph what they did. We felt that for this dataset a thematic approach to the photo-elicitation interviews was also appropriate. However, the presence in the photo-elicitation interview data of references to the photographs, and hence to the visual realm, both by participants and by the researcher, created a framing of participants' experiences to which the thematic analysis also had to attend.

The third set of qualitative data was generated via interviews with people who were, or had recently been, homeless. Our experience of running a focus group with previously homeless individuals indicated that although participants were willing to engage in interactive discussion about their experiences of homelessness, they were concerned to present their own life accounts, or stories, of homelessness. Taking this into account, subsequent individual interviews specifically used a life history approach which enabled participants to narrate their experiences and thus situate the issue of vulnerability in a broader context. Consequently, these accounts required a different analytic approach. To have analysed such accounts through thematic analysis which pulls short segments out of the whole interview, fragmenting it - would not have maintained the integrity of the participants' stories. Accordingly they were analysed using a sociologically informed narrative analysis approach.

Narrative analysis focuses on the social construction of the story and the role that stories play in the construction and presentation of identity (Rosenweld and Ochburg, 1992). Moving beyond the idea that a story is representative of an individual life, attention is focused on the 'joint actions' involved in the production of the story. Plummer's (1995) tri-partite model of the producers (those who tell their story), the coaxers (those who encourage and enable the story to be told) and the consumers (those who read/hear the story) is illustrative of this mode of thinking. Even though the producer (teller), encouraged by the coaxer, draws on real events and experiences to tell the story, the story is only ever an interpretation of the significance of past events and experiences. Finally the consumer will add another layer of meaning and interpretation onto the story. As Riessman (1993) notes, representation is ambiguous and always open to different interpretations. Thus, both the meaning and consequences of a story is always contingent upon first, the social location of those involved in the production and consumption of the story and second, the wider social context in which the story is told. For our purposes here we focus on the producers (the participants) who tell their stories.

In contrast to thematic analysis, narrative analysis begins by identifying the 'sequence' of a story. While 'sequencing' can take many forms, including chronological, consequential or thematic sequencing, it focuses attention on the socially constructed nature of the story. Thus analysis moves beyond the mere identification of past events and experiences to concentrate on trying to understand the 
contemporary significance or meaning they hold for the individual telling the story. Only when a skeleton structure has been completed for each story included in the dataset is it possible to begin to make comparisons between the stories.

To summarise, then, it was epistemologically most appropriate to analyse the in-depth interviews and photo-elicitation studies using a grounded thematic approach, whilst the life history accounts were best analysed through a sociologically informed narrative analysis approach. Even though both the thematic and narrative approaches are located in a social constructionist paradigm, the former focuses on identifying conceptual themes and issues raised by the participants, while the latter attends to the social construction of the story and the role that stories play in the construction and presentation of identity. This represented a potential point of tension for integration in as much as one mode of analysis consists of extracting information from the whole, while the other seeks to maintain the 'wholeness' of the story. Where the goal is analytic integration, a means must be found for reconciling this tension without undermining the contribution of each method to understanding the phenomenon being researched.

\section{Achieving an integrated analysis}

There has been little written about the practicalities of integrating multiple datasets within the parameters of each achieving an equal contribution (with the exception of Coxon, 2005 and Pawson, 1995). To address this challenge in our own research with respect to the heterogeneity of our three qualitative datasets we developed an approach to enable us to be systematic and rigorous which we called 'following a thread' (Moran-Ellis et al, 2004, 2006). This consisted of four steps. The first step entailed each dataset being initially analysed using the analytic method appropriate to that data (as described earlier) resulting in the identification of emergent findings and further analytic questions.
Having undertaken this initial analysis of each dataset, the second step focused on identifying a 'promising' finding within a dataset which could be picked up as a thread to be followed through into the other datasets. The identification of a promising emergent finding may be sparked by the relationship between it and the over-arching research question, or by the resonance of it with one or more of the other datasets. This established a lead for further analysis involving an iterative interrogation of all the datasets.

This led to the third step whereby emergent findings, categories, and codes concerning the thread that was followed into each dataset were juxtaposed to create a data 'repertoire'? This repertoire was then further analysed to refine and extend the analysis of the relationship between the thread and the overarching research question.

Finally, in the fourth step, the findings that Step 3 generated for a particular thread were synthesised with other threads that were similarly picked up and followed. This can be undertaken without predetermining whether the phenomenon being researched is multifaceted, complex or singular, and without prejudicing the contribution each research method can make to the overarching research question.

The following section looks in more detail at this approach in practice. Even though we focus on our qualitative datasets in this chapter, in practice we used this approach to integrate all the PPIMs' data including the quantitative data.

\section{AN EXEMPLAR: FOLLOWING THE 'PHYSICAL SAFETY' THREAD}

In team discussions of the initial analytic findings from our qualitative datasets it became apparent that a particular finding from the visual component - that of the significance of physical safety as a vulnerability to be managed in everyday life resonated strongly with emergent analytic findings in the homeless data and in the sub-set of interviews with the children and 
young people in our study. On this basis we moved to Step 2 and took it up as a 'promising' thread, systematically identifying and analysing 'physical safety' in these and the other datasets we had generated. Through this we identified codes and categories, and generated emergent findings on 'physical safety' for each dataset. This led on to Step 3 where we juxtaposed these to create a data repertoire. This repertoire was then analysed further, with particular emphasis on analytic questions such as whether issues concerning vulnerability and physical safety were persistent features of experiences of vulnerability, the different facets that were revealed by different research methods, and the importance of contexts for how this form of vulnerability was experienced.

Whilst it is interesting that two of our sets of participants - people who are homeless, and children and young people - are usually classified as 'vulnerable' in policy terms, or categorised as members of a vulnerable group in objective measures and conceptualisations of their social position, they were not selected for particular analytic attention on this basis. Rather their data have been given prominence here because of the strong resonances we found between the emergent findings in the analysis of the photo-elicitation interviews, which were conducted with a range of people, and the initial analyses of the data generated with these two groups of participants. Our orientation to all the participants in the study was to their subjective understandings and constructions of vulnerability in their everyday lives, and their accounts of how they strategically manage these vulnerabilities. This precludes any assumptions being made about essentialised or inevitable vulnerabilities for any group of participants in our studies. In this respect, the use of multiple qualitative methods was particularly valuable as it enabled us to gain an extensive and intensive exploration of vulnerability as a subjective interpretive phenomenon. This allowed for people's own understandings and agency and moved away from the overarching deterministic discourses which tend to characterise notions of vulnerable groups and individuals at an objective level.

\section{Step 1 - Initial analysis}

\section{The photo-elicitation interview data}

Thematic analysis of the photo-elicitation interviews suggested that participants associated a threat to physical safety with specific places, groups of people or hazards, with a distinction being made between physical assault and accidents. Photographs of dark alleyways, deserted paths, and graffiti were taken by respondents to represent unsafe places where assaults could occur. Participants often said that they avoided these places, especially at night. Photographs of a fast lorry, a dark street and a blind curve represented potential traffic hazards. Even though participants said that they had to exercise due care, these hazards were constructed as being beyond the control of the individual and responsibility was seen to rest with 'the Council'. In relationship to a photo (of a blurry lorry), one participant commented:

I hate the lorries using this as a rat run to the industrial estate at the end because they make the house shake. The whole road is up in arms about that. (Jane, 37 years old).

Participants made a further distinction between potential threats (either malicious or accidental) to their own safety and threats to other people. In the latter case, participants talked about the threat to specific groups of people - children, the elderly or the disabled - suggesting they saw vulnerability as being an inherent characteristic of these particular groups. One respondent, for example, photographed an uneven pavement which she saw as a potential tripping hazard. She was not concerned for her own safety, but referenced 'vulnerable old people', perhaps with walking sticks, who could easily trip. The same respondent photographed the detritus of drug use but focused her concern on this being found near a primary school:

... it's literally about 50 yards from the back end of the school field and there is a gate that goes from the junior school, to this. It is literally about 50 yards 
and you go down there and they have got, they have made, bits of furniture that have been chucked away, like that was a table and all around there there is paraphernalia, what I call paraphernalia. There is drink cans, there is coke cans where they have made bombs to smoke drugs, there's even silver foil where they have actually, we did have a look and it looked as though they had been smoking heroin and that is a concern, obviously, to the whole of the neighbourhood because any kids of any age can go down there. (Alice, aged 56-65)

Certain types of public space, represented by photographs of alleyways, overgrown passages between buildings and a subway were considered intrinsically unsafe, particularly at night time, due to the potential for physical assault. The canal had a more 'fluid' status as a safe/unsafe place, seen as a recreational amenity during the day but dangerous after dark. In addition, specific groups of people (the homeless, drunk people, local youth gangs) were labelled 'trouble' or 'scary', generally because they represented a potential threat to an individual's safety. Even though participants did not take photographs of people whom they feared - participants cited safety reasons for not photographing these threatening people, but also said that they did not feel comfortable invading the privacy of such individuals - other means were used to indicate the sense of threat felt by participants. For one respondent, a photograph of graffiti was emblematic of a gang of youths who were considered unstoppable due to the support they enjoyed from older male relatives. In contrast, participants took images of graffiti to suggest that crime was generally prevalent in the area where it was found.

Photographs of CCTV cameras were presented as either representing the dual sword of security and surveillance or, in one instance, given that an old man had been physically assaulted twice under the photographed camera, used to question the notion of security implicit in the use of CCTV cameras. In contrast to these examples, photographs of personal spaces - homes, gardens or bedroom - were taken to indicate safe, comfortable places.

Whilst experiences and perceptions of vulnerability were represented visually in the photographs as well as elaborated in the accompanying photo-elicitation interviews, it was only in the latter interviews that people talked about how they managed potential threats to their physical safety. From this verbal data we identified three key strategies which participants used to minimise either actual risk or their perception of risk. The first strategy was to avoid places or people categorised as unsafe. The second was related to the degree of familiarity participants felt about their local environment. While a high degree of familiarity could be used to aid decisions about which places or groups of people to avoid, it was also used to 'offset' feelings of insecurity or a lack of safety. One woman, for example, claimed that she felt safe living in the neighbourhood despite knowing that other people had been assaulted there. She had lived in the neighbourhood for a long time and was familiar with it, and so felt it was safe. This links to the third strategy of displacing the perception of risk to oneself onto groups of people already designated vulnerable.

\section{Step 2 - Picking up the promising thread of 'physical safety'}

The accounts of children and young people Picking up the thread of physical safety in the interviews with children and young people, the analysis showed that these participants were often making decisions, and taking actions in relation to their safety, based on other people's worries and concerns rather than their own. In particular they were subject to the worries and concerns of their parent(s), which varied in terms of what the worry was, and how strongly it was a factor in parental moves to constrain their child's actions:

l: $\quad$ are there any [...] rules that your parents set [about using the internet]

$P$ : not really but they don't let us have hotmail because of the chat room, my sister had it but I don't know what she did but then they banned it ... so I don't get the benefit which I think is really unfair as all my friends have it and I'm the only one who doesn't have it

I: do you understand the reasons why you can't have it? 
P: not really, I asked but they wouldn't tell me (Tom, age 13 years)

The children in our study, aged 10-13, indicated they were constrained concerning their actions, the places they could go, and how they got there. In general they accepted these limitations whilst also wishing for, and indeed trying to gain, greater autonomy in their movement in public spaces. Two of the children who had recently started cycling into the town centre on their own identified this as an extension of their usual domains beyond the house and garden. Undertaking this venture was accompanied by an acute awareness that they needed to guard their safety in respect of being in the town unaccompanied by an adult. Thus the threat, and their physical vulnerability, was associated with being in a particular place without the protection of an adult rather than the hazard of cycling on the roads (the latter being a safety issue they did not mention). Another child spoke of his sense of a particular threat to his safety when he was not in the company of a protective adult:

I: What is it about strangers that you worry about?

P: $\quad$ Kidnapped

(Jack, 13 years old)

Indeed for some children the threat of being kidnapped or murdered framed their reflections on whether there were places in the town that they might not go, or where they had to be careful. These threats were 'monstrous' but at the same time the children outlined their strategies for maximising their safety, primarily through being able to identify people who might pose such a threat:

P: If I like see someone who doesn't, if it's late or something and I find, if I see someone who doesn't look like normal than I just walk off with my mates and go somewhere else.

I: $\quad[$...] what kind of things do you look for when you're trying to decide if someone's OK or a bit.?

P: It's just like if he doesn't look right, they're watching and things.

(Stuart, age 12 years)
Constraints related to safety were also often contingent on time of day. The arrival of 'the dark' was a particularly important marker of a shift from a safe time to an unsafe time. In this respect, the temporality of safety and threat resonated with a similar framing by adults as well as children in the visual data accounts. However, in the visual data it was named places that became less safe with the arrival of night time, whilst in the interviews with the children parental fears were understood as being simply about 'the dark':

I: What about when you are outside playing? Are there rules about where you can go or what time?

P: Sometimes I am not allowed to go to the park I have to stay right in front [garden]. And we are not allowed to come home really late.

I: What is late, what would be late?

$P$ : Well, when it gets dark. When it gets dark. (Yasmin, 11 years old)

In contrast young people,generally aged 14-18, felt that these worries about safety belonged really to their parents and did not reflect the safety issues that they actually had to deal with when they were out and about in public spaces. These young people identified having to deal with threats of violence: some of the places they went - the amusement arcade, the town centre - opened up the possibility that they might encounter individuals who wanted to fight, gangs, or general violence. Thus, it was important to know when to leave a place and who to avoid. Furthermore, young people often worked to manage their parents so they did not find out about these hazards, for example by withholding information as to their true whereabouts or by presenting themselves in ways designed primarily to reassure their parents:

I go to my friend's house and we'l| go out, and I'll just text my parents and say we've gone here, there or wherever. If I'm staying at a friend's house, I will go out with them but won't tell my parents (Lucy, 14 years old).

While space does not permit a full discussion here, one of the girls in the study also talked about managing gendered threats to her safety 
from men, whilst another indicated that this was a parental worry that she had to negotiate in order to be allowed out with her friends or on her own.

Young people who articulated a definition of vulnerability tended to associate it with the ability or inability to defend oneself physically from attack.

The narrative data: Stories of homelessness Picking up the thread in the narrative interviews with people who were homeless, the analysis revealed the ways in which the topic of physical safety in the accounts of people who had experienced homelessness was a salient factor in both the construction of identity, and the material practices of daily life. Physical safety - the lack of it, the search for it, the meaning of it - was an integral part of individual stories.

Many participants presented biographical, chronologically structured accounts of their lives which highlighted the lived experience of vulnerability and its links to (a lack of) physical safety. This included, for example, physical, sexual and emotional abuse in childhood, experiences of being street homeless, the physical dangers inherent in alcohol and/or drug abuse, or the transient nature of many homeless people's lives. At the individual level it was evident that the majority of the stories were structured around the 'quest' for physical safety; taken collectively it was possible to chart the different 'stages' involved in homelessness, the strategies developed at each stage to deal with the experience, and the subsequent impact on identity.

One young man - David - for example, had become homeless in his home town and had lived for a short period of time in a car, yet had felt safe doing so because of his familiarity with the area and the people. This contrasted sharply with his recent experiences of living in a night shelter. His lack of familiarity with the area, coupled with his perception that local people were actively hostile to homeless people not only led him to reflect on the salience of this new identity for him but also to develop strategies to publicly hide this identity: he avoided mixing with other homeless people in public therefore hoping to 'pass' as a general member of the public, thus remaining safe. Another resident of the night shelter - Tom, a man in his late thirties and homeless since the age of 14 - had developed additional strategies to cope with the physical threats that arise from being street homeless. On arriving in a new and unfamiliar environment he applied knowledge gained in previous locations to the new location, in short constructing a 'universalised' safety 'map'. For example, previous experiences had taught him that the chances of being physically attacked were higher if he slept in the centre of a town as opposed to the outskirts, thus he routinely avoided the centre of all towns.

Participants who had been through drug and/or alcohol rehabilitation and were currently living in residential move-on accommodation, from which they hoped to move to individual permanent accommodation, were at a different stage and this was reflected not only in the telling of their stories but also in their reflections on physical safety. While producing in-depth accounts of past threats to physical safety, the majority felt physically safe in the present although recognising that this was contingent upon remaining alcohol and/or drug free. Looking to the future, participants expressed concerns that they might be housed in areas populated by drug users and dealers, which would constitute a new threat to their physical safety.

These participants adopted a number of strategies to reduce threats to their physical safety, including avoidance, 'invisibility' and 'passing'. Additionally, recovery from alcohol and/or drug abuse was often talked about in terms of a long-term strategy to reduce the risk of physical harm, in as much as the ultimate goal is permanent accommodation and reintegration into 'mainstream' society. In addition, participants' explanations for why they left home could be construed as a strategic act of resistance, whereby being homeless was considerably preferable to being subjected to further abuse at home.

In the discussion of the previous two datasets it was possible to use data extracts 
from the interviews to illustrate our analysis. Unfortunately, a combination of a lack of space and methodological considerations does not permit the inclusion of data extracts from the homeless accounts - one 'extract' ran to some 12 pages of transcription. In order to do justice to the data we would need to present extended data extracts to demonstrate the narrative nature of the accounts and the presentation of identity. One man, for example, began his interview by asking if the interviewer wanted the story of his life and then proceeded to provide a very detailed chronologically ordered account of his life, which attempted to provide a socially situated explanation for his homelessness. Drawing on the notion of 'discredited identities' (Goffman, 1963) it is possible to see how the interview provided the homeless participants with the opportunity to provide an alternative account of homelessness from the negative one traditionally portrayed in society.

\section{Step 3 - Creating a data repertoire}

The third step of this process of analytic integration involved juxtaposing both the initial analytic findings of the individual datasets and the data segments/elements that had been coded in the initial analysis to create a data repertoire for the theme of 'physical safety'. This was then subjected to further analysis and interpretation, looking for commonalities and differences, convergences and divergences. Effectively this repeats the process of inductive analysis with the data identified as salient to the thread of physical safety whilst remaining mindful of the implications of the nature of the data and its origin. It is through the development of the analysis of the data repertoire that findings can be integrated to produce a more complex understanding of the thread and its relationship to the overall research question.

In relation to physical safety and vulnerability, further analysis of our data repertoire led us to understand physical safety as both a present and an embedded past feature of the lives of people who were homeless, a present but negotiable hazard for young people not living with violence, and a visually locatable phenomenon for all participants. For young children the concept was often related to extraordinary events (kidnap, murder) rather than more ordinary or frequent threats to physical safety such as road traffic accidents, muggings, or assault.

Contingent features of vulnerability also emerged out of the analytic integration of the three datasets. These included vulnerabilities associated with physical safety which were contingent on time of day/night as well as being linked to material-spatial-architectural aspects of public spaces. In terms of dealing with situations and locations which increased perceptions or senses of physical vulnerability, all participants identified strategies which they used to manage their (potential) vulnerability.

It became clear that perceptions, constructions and experiences of vulnerability also diverged in different domains for different groups of participants. For people who were homeless, vulnerability was closely tied to the biographies that had led them to be without a home. They identified physical assault as a recurrent feature of their childhood homes, their temporary homes in their adult lives, and of their times living on the street. In addition, threats to their physical safety were encountered, or anticipated, when moving into new areas or new towns and occasioned the need to make decisions about where they would stay and where they would locate themselves. Physical vulnerability was tied into the identity of being homeless in a profoundly biographical and narrative way.

In contrast the physical safety issues that concerned children and young people in our study reflected the ways in which they are positioned between structures which constrain their actions on the basis of their age, and their own desires, opportunities, and abilities to be (relatively) autonomous social actors (see Hutchby and Moran-Ellis, 1998; James and Prout, 1990). In this regard their constructions of physical safety and vulnerability were linked to the relative distributions of power between adults and children/young people, and the ways in which 
these distributions intersect with their social worlds. For the children in the study, their sense of vulnerability in physical terms related to extending their usual geographical range from their immediate localities with known adults nearby to being unaccompanied in public spaces at a further distance from home. They managed their vulnerability by adhering to parental rules which they understood to be designed to maximise their safety, and by developing their own readings of other people in their vicinity in terms of whether or not they might present a threat. For the young people in the study their social worlds were already more extended both geographically and temporally, but they sought greater control and autonomy in their movements and activities. With this came an increased likelihood of having to deal with physical safety issues, with threats presented by others in the form of fights, gang actions, violent encounters, and possible sexual harassment or assault. Key for the young people in the study was managing parental concerns so that the young people could exercise physical autonomy in the face of other people's worries about their vulnerability whilst balancing this with managing the potential risk of actual violence when they were in the public arena. Their perception of their own physical vulnerability was framed in the context of their strength or weakness relevant to their potential assailant.

Physical safety and vulnerability took on a different dimension in the domain of the visual as represented in the photoelicitation interviews. Here it was the material fabric of places which were invoked visually and verbally as increasing or decreasing vulnerability to physical hazards and assaults. The built environment was taken to be a context in which a person's vulnerability may be accentuated - for example that of older people who might trip over loose paving, or children who were at secondary risk to the hazards of drug taking near their school. This material context intersected with ideas of time of day and sources of responsibility to produce physical vulnerability as a product of ecology on the one hand and an inherent characteristic for some on the other. Physical vulnerability can be understood in visual terms as readings of present dangers, future dangers, and attributed responsibility for causing the vulnerability to outside agents such as the Council, or a local group of youths. Strategies for managing safety were not manifested in the visual domain, emerging instead as accounts of actions including avoidance of the location.

In summary then, physical safety emerges as a dimension of vulnerability but how it emerges is contextual to the social worlds of the participants. How people experience vulnerability, and how they act on that, varies considerably whilst the environment presents different degrees of threat. For the homeless people in the study physical safety was a key strand in their narratives, interweaving with their identities and biographies. For the young people and children it was a site around which the relationship between their structural position in their families, and in society more generally, and their status as social actors is played out. Visually, the notion of physical safety can be framed by participants as a material, ecologically located phenomenon.

Uniting these dimensions brought us to considerations of vulnerability and safety which suggested that, whilst there were commonalities of dimensions across different genres of experience and perception, such as the significance of time and place, this form of vulnerability also intersected with individuals' notions of their own and others' identities. This led us towards theorising how this aspect of vulnerability and its intersection with (or contribution to) individual identities fits with other forms of vulnerability. To address this question we returned to the data to identify other 'promising threads' and followed those analytically across the datasets. The final goal was to synthesise these findings with other themes, to create multi-faceted understandings of vulnerability and its management in everyday life across a broad range of dimensions that emerged from our research. At the end our theoretical understandings of vulnerability 
was a picture woven from these different threads.

\section{CONCLUSION}

\section{Challenges in this approach}

Our goal in this chapter has been to demonstrate how integration of different qualitative datasets, through an examination of each set of findings relating to safety and vulnerability, increased our understanding of the experience of vulnerability. Each dataset contributed an equal share to the analysis of vulnerability and physical safety, and as the analysis proceeded, we were able to reflect on the complex nature of vulnerability in this regard.

This process for generating analytic integration is time-intensive and entails a number of challenges. The first is identifying 'promising' threads. There are a number of strategies used in single dataset analyses which can be drawn on: inductive leads may arise from within the project, through reference to the research question or sensitivity to the content of the data, or it may be sparked externally, so to speak, by the stimulus of theoretical work and other empirical studies. In addition, team discussions about dataset contents, emergent findings, and puzzling questions are essential for establishing resonances between the datasets. Thus it is important that team research includes team members with a range of expertise, allows for appropriate methodological divisions of labour, and includes sufficient opportunities for good communication within the team.

Another key challenge is to allow each dataset its own integrity throughout the integration process. Creating a data repertoire of systematically identified initial analyses, assembled for further analysis to produce an integrated story about a particular aspect of the phenomenon (such as we have in done in this chapter with respect to physical safety and vulnerability), might seem to privilege a thematic approach to analysis. If this were the case, it would be problematic for data more appropriately handled by other analytic approaches. In respect to this, the PPIMs team critically examined what happened to the narrative accounts of the homeless people when the data repertoire was created. Our conclusion was that the data repertoire could encompass narratives provided effort is made to preserve their integrity by constantly reexamining the links between the themes and the narratives. In our case, the overarching structural narrative feature, which was paramount to our understanding of the homeless participants' accounts, draws on notions of identity as a homeless person. The theme of physical safety extended beyond specific instantiations to form a cornerstone of identity. We suggest that the salience of identity in these accounts complements those produced by other participants and resulted in an increased understanding of the theme of physical safety and the overall theme of vulnerability.

Nevertheless, the potential 'risk' of some types of data being 'translated' into other types remains. We successfully retained the narrative quality of the homeless data; however, we were unable to convey a sense of the story-ness of the data in a short chapter such as this. Similarly, in this chapter we described photographs, thereby translating visual data into verbal, and relied on the transcriptions of the photo-elicitations (textual data) leaving aside actual visual analysis which was also part of the study. The photo-elicitation draws on the visual knowledge of the study participants and is therefore distinct from the other interview data. We believe that visual data itself, as with narrative data, can be part of analytical integration; however, conventional reporting and publishing formats provide challenges in presenting such data in their own terms.

In this chapter we have argued, drawing on our earlier work, that integration should be thought of as a process which creates, and analytically exploits, a particular relationship between different sets of data. We have also argued that since all qualitative data are not alike attention must be paid to the processes by which research generating multiple qualitative datasets will achieve 
integration, where that is the purpose of having a multiple methods research design.. To this end we have presented a model for the practical accomplishment of integration at the level of analysis - 'following the thread' which focuses on ensuring that the integrity of each type of dataset is preserved in the process of integration, and hence the epistemological contribution of each set of data is maintained. We also argue that this approach offers the opportunity for synergies between datasets in order to achieve one of the goals of multiplemethods research: the generation of an overall analysis which is greater than the sum of the (methodological) parts.

\section{NOTES}

1 ESRC Award H333250054 Investigating Practice and Process in Integrating Methodologies (PPIMs). The project is funded by the ESRC under the Research Methods Programme http://www.ccsr.ac.uk/methods/.

2 A pseudonym for a small town in the South of England. All participants are anonymised.

3 This alludes to a repertoire of dance or music pieces, rehearsed and developed, which provide a pool from which a selection is made to create a particular conceptual performance. We use this to capture the assemblage of initial analyses which are not 'raw' data, have their own (methodological) integrity, and which can be brought together to produce a coherent 'story'. We would not, however, wish the metaphor to be taken too far: the intention is to provide some language to describe this part of the process of integrated analysis.

\section{REFERENCES}

Brannen, J. (2004). 'Mixing methods: the entry of qualitative and quantitative approaches into the research process', International Journal of Social Research Methodology, 8(3):173-184.

Bryman, A. (2004). Social Research Methods, second edition. Oxford: Oxford University Press.

Caracelli, V.J. and Greene, J. (1997). Advances in MixedMethod Evaluation: The Challenges and Benefits of Integrating Diverse Paradigms, New Directions for Evaluation, No. 74. San Francisco, CA: Jossey-Bass.

Coffey, A., and Atkinson, P. (1996). Making Sense of Qualitative Data Analysis: Complementary Strategies. Thousand Oaks, CA: Sage.
Collier, J. (1967). Visual Anthropology: Photography as a Research Method. New York: Holt, Rinehart and Winston.

Corden, A., and Sainsbury, R. (2006). 'Exploring 'quality': research participants' perspectives on verbatim quotations', International Journal of Social Research Methodology, 9(2):97-110.

Coxon, T. (2005). 'Integrating qualitative and quantitative data: What does the user need?' FQS (Forum: Qualitative Social Research). 6 (2): e-paper. http://www.qualitative-research.net/fqs/ fqs-eng.htm. Accessed July 2006.

Dicks, B., Soyinka, B., and Coffey, A. (2006). 'Multimodal ethnography', Qualitative Research, 6(1): 77-96.

Goffman, Erving. (1963). Stigma: Notes on the Management of Spoiled Identity. Englewood Cliffs, NJ: Prentice Hall.

Greene, J.C., Caracelli, V.J., and Graham, W.F. (1989). 'Toward a conceptual framework for mixed-method evaluation designs', Educational Evaluation and Policy Analysis, 11:225-274.

Hutchby, I., and Moran-Ellis, J. (eds) (1998). Children and Social Competence: Arenas of Action. London: Falmer Press.

James, A., and Prout, A. (eds) (1990). Constructing and Reconstructing Childhood. London: Falmer Press.

Mason, J. (2006). 'Mixing methods in a qualitatively driven way', Qualitative Research, 6(1): 9-25.

Moran-Ellis, J., Alexander, V.D., Cronin, A., Dickinson, M., Fielding, J., Sleney, J., and Thomas, H. (2004). Following a Thread - An Approach to Integrating Multi-method Data Sets, paper given at ESRC Research Methods Programme, Methods Festival Conference, Oxford, July 2004.

Moran-Ellis, J., Alexander, V.D., Cronin, A., Dickinson, M., Fielding, J., and Thomas, H. (2006). 'Triangulation and integration: Processes, claims and implications', Qualitative Research, 6(1): 45-59.

Pawson, R. (1995). 'Quality and quantity, agency and structure, mechanism and context, dons and cons', BMS, Bulletin de Methodologie Sociologique, 47:5-48.

Plummer, K. (1995). Telling Sexual Stories: Power, Change and Social Worlds. London: Routledge.

Riessman, C.K. (1993). Narrative Analysis. London: Sage.

Rosenweld, G.C. and Ochberg, R.L. (1992). Storied Lives: The Cultural Politics of Self-understanding. London: Yale University Press.

Wisner, B. (1991). 'Rural livelihoods in Kenya, 1971-1990: Further reflections on justice and sustainability'. Paper presented to the Association of American Geographers, Miami. 